\title{
Detection of Total Dissolved Solids from Landsat 8 OLI Image in Coastal Bangladesh
}

\author{
Jannatul Ferdous $^{1 *}$, M Tauhid Ur Rahman ${ }^{2}$, Sumit Kumar Ghosh ${ }^{1}$ \\ ${ }^{I}$ Climate Change Lab, Department of Civil Engineering, Military Institute of Science and Technology \\ Bangladesh \\ ${ }^{2}$ Department of Civil Engineering, Military Institute of Science and Technology, Bangladesh
}

\begin{abstract}
Quality of coastal surface and groundwater is deteriorating day-by-day due to the combined effects of climate change and unwise activities of coastal people. Total Dissolved Solids (TDS) is an important water quality parameter that can be monitored regularly more conveniently by remote sensing techniques. This study aims to evaluate the applicability of Landsat 8 OLI images to detect TDS of surface water of coastal Bangladesh. It employs 14 different band compositions to compute an equation through multiple regression analysis among the band values and 18 sample TDS values collected from field visit in the last week of November 2018. Level 2 product of Landsat 8 OLI image (path/row: 138/44) dated 27 November 2018 has been used for the analysis. A regression equation has been computed with the bands Blue, Green and Red, which can predict TDS (mg/L) 83.6\% correctly. Analysis of change detection study revealed that water areas with TDS level $100-600 \mathrm{mg} / \mathrm{L}$ have been reduced $28.9 \%$ and water areas with unacceptable TDS level $(>1200$ $\mathrm{mg} / \mathrm{L}$ ) have been increased $32.7 \%$ between 2014 and 2018. Contamination of surface waters has led to freshwater scarcity and health hazard for the coastal people.
\end{abstract}

Keywords: Coastal Bangladesh, Landsat 8 OLI, Total Dissolved Solids (TDS), Multiple Regression

\section{Introduction}

The most important natural resources on earth to sustain human life and the environment is water. Water quality is the key to all these roles and unsafe drinking water possess severe threats to human existence (Miah et al. 2015, Das et al. 2017). Water quality is the measure of the suitability of water for a particular use, which can be decided by comparing with some numerical standards (Yusop et al. 2011). Monitoring of water quality is one of our main concerns as it is related to the well-being of human and ecosystems health (Yusop et al. 2011, González-Márquez et al. 2018). Water quality monitoring can be done in the conventional way including collection of numerous samples from field and testing them in laboratory, which gives more correct results but takes more time and resource (Yusop et al. 2011). Remote sensing techniques with its various applications make the monitoring task very effective in terms of time and resource (Su et al. 2008, Kulkarni, 2011, Yusop et al. 2011). The optical characteristics of water depends on its parameters and it can be altered by variation on the concentration and character of suspended and dissolved solids and other organic matters etc. (Hellweger et al. 2004, Pavelsky and Smith, 2009, González-Márquez et al. 2018). So satellite images can detect the water quality parameters depending on their optical characteristics.

Coastal water sources are very vulnerable to saline water intrusion due to storm surges and high tidal flows and decreasing upstream flow discharge and this vulnerability is increasing day by day due to anthropogenic causes (Su et al. 2008, Miah et al. 2015). In coastal Bangladesh, natural waterbodies are affected by salinity and other organic matters due to storm surges, upstream withdrawal of freshwater and shrimp farming (Khan et al. 2011, Miah et al. 2015). Coastal people are dependent on 
these water sources for drinking, irrigation and other domestic purposes. So the quality of these waterbodies should be monitored regularly and any degradation in the quality should be reported for better management. Regular monitoring of the parameters can be done from the satellite images by developing a model which can detect the parameters almost correctly. Many researchers have developed several numerical models to detect water quality parameters like presence of metal ions, turbidity, total dissolved solids and total suspended solids etc. from satellite images, most common is Landsat images (Hellweger et al. 2004, Lim et al. 2009, Karakaya et al. 2011, Kulkarni, 2011, Yusop et al. 2011, Pásler and Komárková, 2016, González-Márquez et al. 2018). But there is a huge research gap in case of coastal Bangladesh.

This study aims to evaluate the applicability of Landsat 8 OLI images to detect TDS of surface water of coastal Bangladesh. For this TDS values from field visit have been collected and these values have been used to study the correlation between field values and reflectance values of different bands of Landsat 8 OLI. A multiple regression equation has been generated and the equation has been employed for change detection study of TDS level of surface water between 2014 and 2018. Similar studies can be conducted with all the water quality parameters. These multiple regression equations will ease the monitoring task very efficient by saving time and resources.

\section{Materials and Methods}

To study the correlation between Landsat 8 OLI band values and TDS level of surface water of coastal Bangladesh, both primary and secondary data have been employed. A field visit to Upazilas of Satkhira district has been conducted in the last week of November 2018. TDS levels of total of 18 sample locations of surface water have been measured with EC meter (Figure 1). On the other hand, Level 2 product of Landsat 8 OLI image (path/row: 138/44) dated 27 November 2018 has been collected from United States Geological Survey (USGS) website to evaluate the relationship between field TDS values and band values. Figure 1 shows the sample collection locations from Satkhira district. 


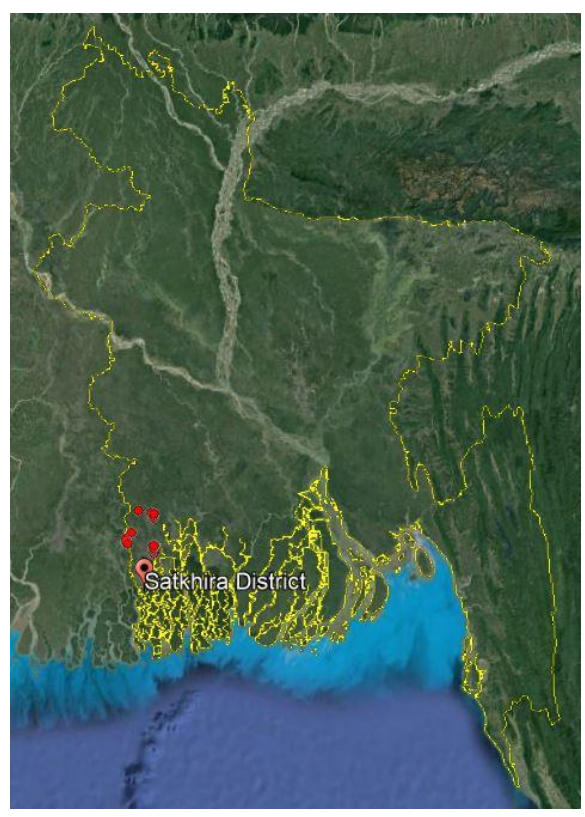

Figure 1 Sample collection locations in Satkhira district

Total 14 band compositions with the bands Blue, Green, Red, and Near Infra-red have been selected for the correlation study. Band values have been extracted for the sample locations and coefficient of determination $\left(r^{2}\right)$ has been computed between the band values and field values. Depending on the higher $\mathrm{r}^{2}$ values, 7 band compositions have been identified for the multiple regression analysis (Table 2). Online calculator has been used to carry out the multiple regression analysis (Statistics Kingdom, 2018). After 5 iterations, the regression analysis showed a significant relationship and gave an equation with Blue, Green and Red bands (Equation 2). Using the equation, change detection study has also been carried out. For this, Landsat 8 OLI images of the year 2014 and 2018 have been employed. Table 1 represents the detail of satellite images used for change detection study. 
Landsat 8 OLI Image downloaded from

USGS website (path/row: 138/44, dated 27

November 2018)
TDS level of 18 sample locations collected from field visit to Satkhira district

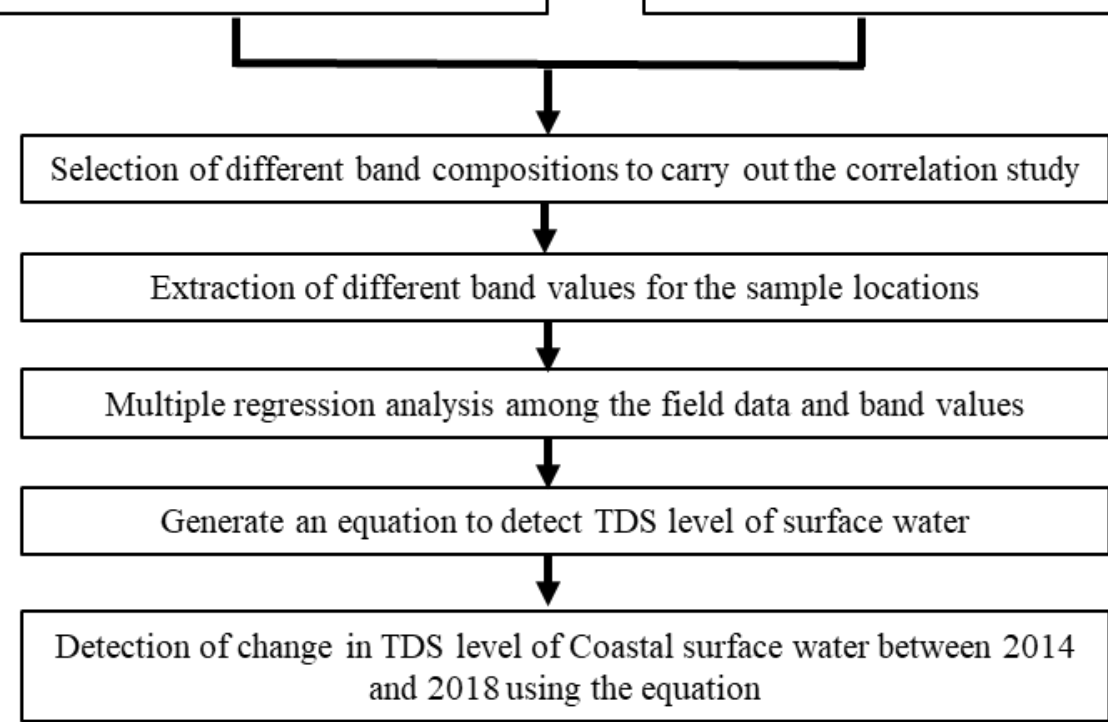

Figure 2 Methodological flow chart of the study

Table 1 Details of images used for Change Detection Study

\begin{tabular}{lll}
\hline Sensor & Path/Row & Date of Acquisition \\
\hline \multirow{3}{*}{ Landsat 8 OLI } & $137 / 44$ & $25-11-2014$ \\
\cline { 2 - 3 } & $138 / 44$ & $16-11-2014$ \\
\cline { 2 - 3 } & $137 / 44$ & $20-11-2018$ \\
\hline $138 / 44$ & $27-11-2018$ \\
\hline
\end{tabular}

After acquiring the images, Blue, Green, Red and Near Infra-Red (NIR) bands of the images were stacked and finally, the two scenes were mosaicked together. From the mosaicked images, the area of interest has been extracted. Area of Interest has been delineated to cover as much as coastal areas from the scenes (Figure 3).

From the extracted images, water bodies for both years have been identified within the area of interest using the threshold value of Normalized Difference Water Index (NDWI) (Equation 1). Positive NDWI indicates water bodies (McFeeters, 1996). 
After identifying water bodies, the TDS level of those water bodies has been computed using the generated equation (Equation 2). TDS level has been classified into six classes to compare the change between 2014 and 2018.

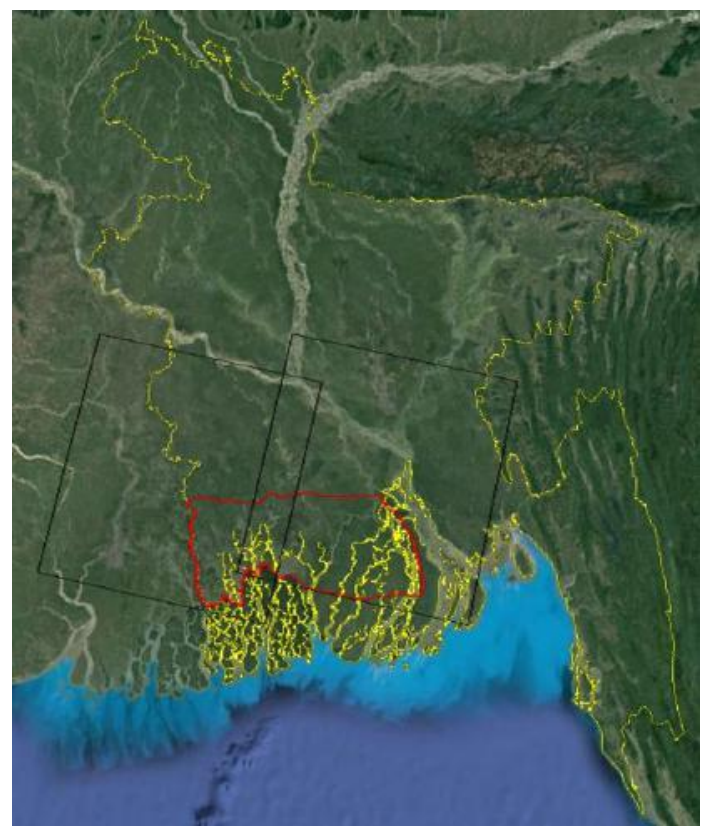

Figure 3 Area of Interest for Change Detection Study of TDS level of Surface Water of Coastal Bangladesh

\section{Results and Discussions}

Total 14 band compositions have been employed initially to compute $\mathrm{r}^{2}$ values and from them, 7 band compositions have been identified according to their higher $\mathrm{r}^{2}$ value. Table 2 shows the band compositions and their associated $\mathrm{r}^{2}$ values with field values. Used band compositions for the regression analysis are - Blue, Green, Red, Blue and Green, Blue and Red, Green and Red, Blue and Green and Red.

Table 2 Coefficient of Determination $\left(r^{2}\right)$ values for different Band Compositions of Landsat 8 OLI (Level 2) to detect TDS of Surface Water in Coastal Bangladesh

\begin{tabular}{llll}
\hline Band Compositions & R2 Value & Band Compositions & R2 Value \\
\hline Blue (B) & 0.738 & G*R & 0.611 \\
\hline Green (G) & 0.632 & G*NIR & 0.028 \\
\hline Red (R) & 0.598 & $\mathrm{R}^{*} \mathrm{NIR}$ & 0.001 \\
\hline Near Infra-Red (NIR) & 0.357 & $\mathrm{~B}^{*} \mathrm{G} * \mathrm{R}$ & 0.674 \\
\hline $\mathrm{B}$ G & 0.711 & $\mathrm{~B}^{*} \mathrm{G} * \mathrm{NIR}$ & 0.185 \\
\hline $\mathrm{B} * \mathrm{R}$ & 0.693 & $\mathrm{~B} \mathrm{R}^{*} \mathrm{NIR}$ & 0.219 \\
\hline $\mathrm{B} * \mathrm{NIR}$ & 0.029 & $\mathrm{G} \mathrm{R}^{*} \mathrm{NIR}$ & 0.101 \\
\hline
\end{tabular}


For detecting the TDS level of surface water of Coastal Bangladesh, an equation has been generated through multiple regression analysis using the selected 7 band compositions (Equation 2).

$$
\mathrm{TDS}(\mathrm{mg} / \mathrm{L})=-3311.4364+41.3237 * \mathrm{R}-0.0779 * \mathrm{G} * \mathrm{R}+0.00006353 * \mathrm{~B} * \mathrm{G} * \mathrm{R}
$$

This equation is able to predict the TDS level of coastal surface water from Landsat 8 OLI images $83.6 \%$ correctly (Figure 4$)$. The p-value (0.000009355) indicates significant correlation.

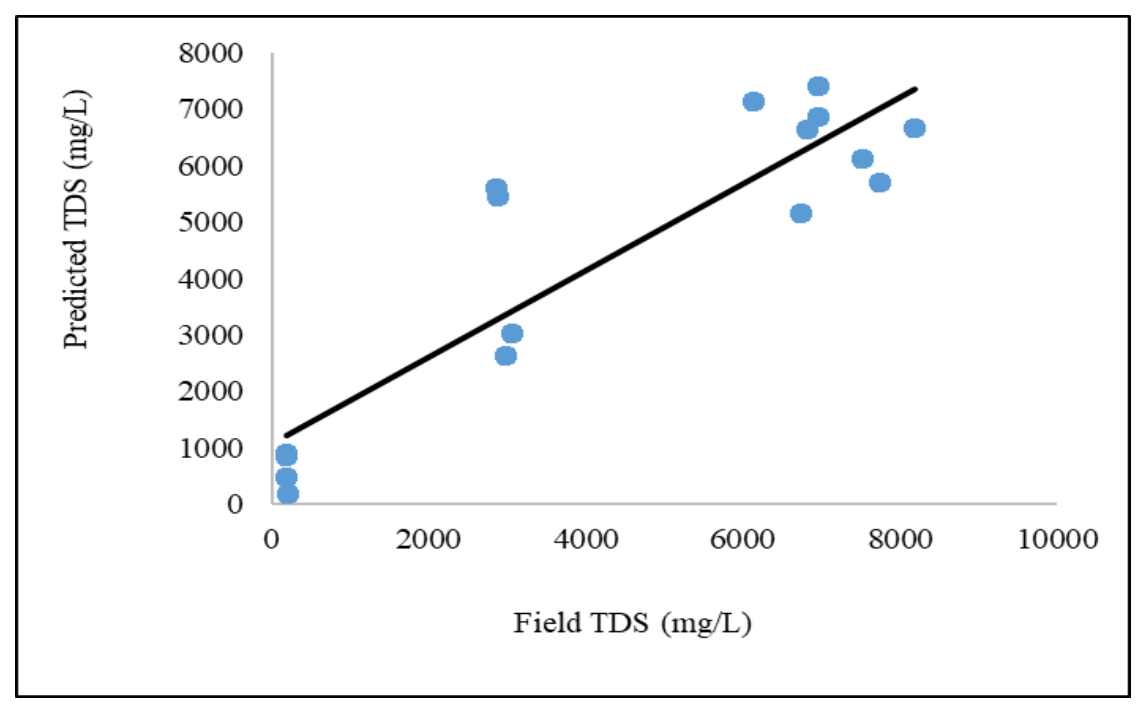

Figure 4 Relation between field TDS and Predicted TDS for Landsat 8 OLI Level 2 Product

TDS level of surface water can be easily detected from the Blue, Green and Red bands of Landsat 8 OLI, which makes the monitoring of water quality more convenient. This equation has also been used to study the change in TDS level of surface water of Coastal Bangladesh between 2014 and 2018. After identifying the waterbodies of coastal region for these years using the threshold value of NDWI (NDWI>0), TDS level has been calculated and classified into six classes (Islam et al. 2016). Table 3 represents the classification detail of TDS level and areas under these limits in 2014 and 2018.

From the change detection study, it has been revealed that the TDS level of coastal surface water is showing an increasing trend between 2014 and 2018. About $49.4 \%$ of water areas were under unacceptable class in 2014, which has been increased (32.7\%) to $65.5 \%$ in 2018 . In 2014, only $3.5 \%$ of water areas were under excellent class, which has been reduced (28.9\%) to $2.6 \%$ (28.9\%) in 2018 (Figure 5). 
Proceedings of the $3^{\text {rd }}$ International Conference on Climate Change, Vol. 3, 2019, pp. 35-44

Table 3 Water areas under different TDS level in 2014 and 2018 in Coastal Bangladesh

\begin{tabular}{llll}
\hline \multirow{2}{*}{ TDS $(\mathrm{mg} / \mathrm{L})$} & Status & \multicolumn{2}{c}{ Areas in \% of total water areas } \\
\cline { 3 - 4 } & & 2014 & 2018 \\
\hline Less than 100 & Insipid Taste & 28.2 & 18.5 \\
\hline $\mathbf{1 0 0}$ to $\mathbf{3 0 0}$ & Excellent & $\mathbf{3 . 5}$ & $\mathbf{2 . 6}$ \\
\hline 300 to 600 & Good & 6 & 4.1 \\
\hline 600 to 900 & Fair & 6.4 & 4.5 \\
\hline 900 to 1200 & Poor & 6.5 & 4.8 \\
\hline More than $\mathbf{1 2 0 0}$ & Unacceptable & $\mathbf{4 9 . 4}$ & $\mathbf{6 5 . 5}$ \\
\hline
\end{tabular}
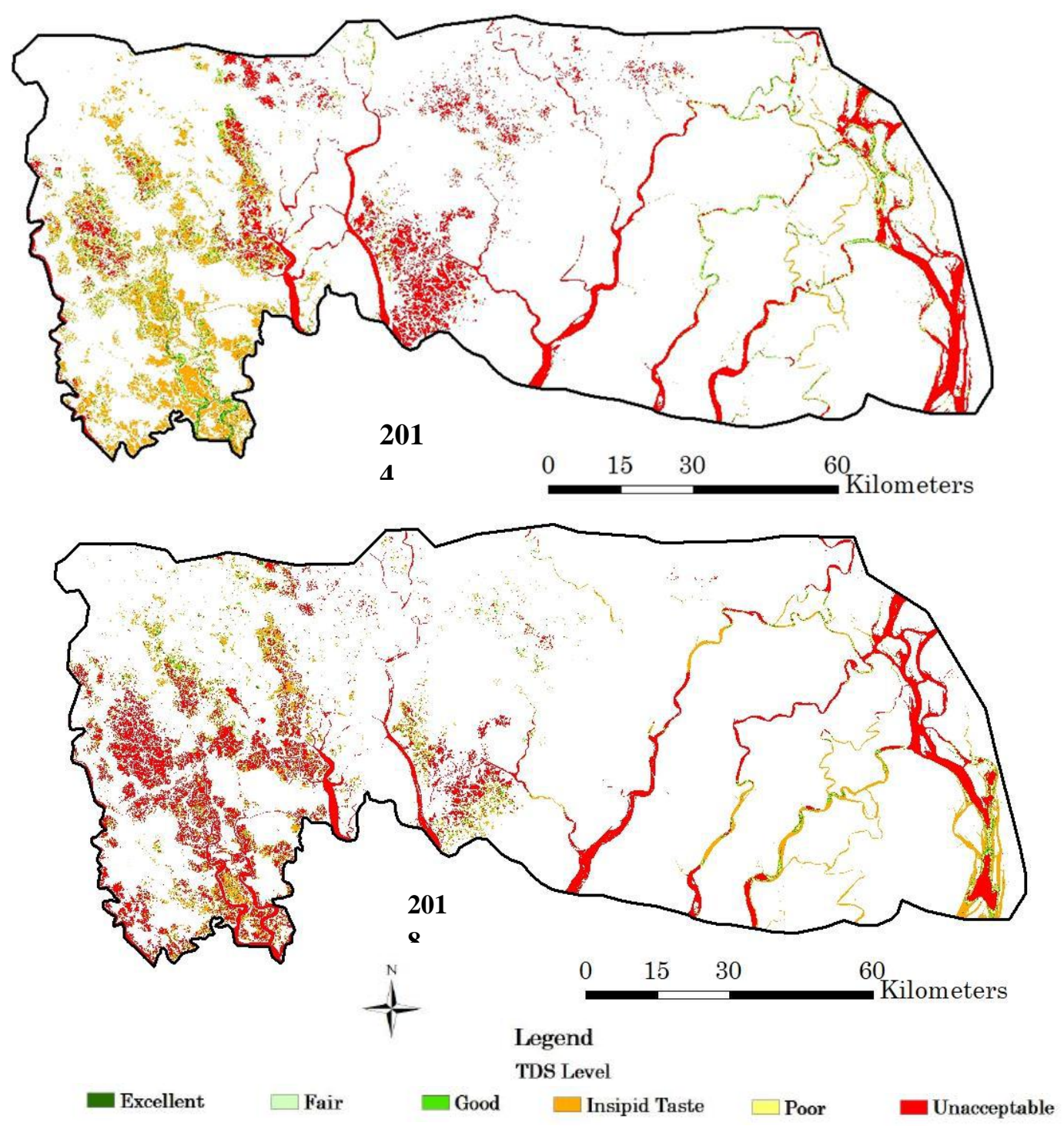

Figure 5 Change of TDS Level of Surface Water of Coastal Bangladesh between 2014 and 2018 
High TDS level indicates the surface water is not fresh and it does not contain all the minerals (Rahman et al. 2017). This is not suitable for cultivation and hatchery. It may also be aesthetically unsatisfactory for domestic uses like bathing and washing. Water with high TDS value makes it less palatable and it may cause a negative physiological reaction in consumer and even may cause gastrointestinal irritation and constipation effects (Jothivenkatachalam et al. 2010, Miah et al. 2015). TDS level of coastal water bodies is increasing and becoming unacceptable. The water bodies of Satkhira district have been gone through significant changes (Figure 5). Das et al. (2017) and Rahman et al. (2017) also reported that Satkhira district, especially Shyamnagar Upazila has experienced severe degradation in its drinking water quality both in terms of Salinity and TDS level. TDS level and Salinity are very similar concept as most dissolved solids typically consist of inorganic ions, which are the components of salts. So, the reason of increasing TDS is similar as increasing salinity in coastal Bangladesh. Water quality of coastal areas is deteriorating day by day because of human activities like mining, untreated waste disposal, use of pesticides and excessive presence of metal ions (Ahmed et al. 2011, Miah et al. 2015). Surface water of coastal Bangladesh is affected by upstream flow discharge and saltwater intrusion from the Bay of Bengal, storm surges and upstream withdrawal of freshwater (Su et al. 2008, Khan et al. 2011, Miah et al. 2015). Coastal Bangladesh was severely affected by Cyclone AILA in 2009, which caused inundation of many drinking water sources with saline tidal water and made them unsuitable for drinking and irrigation (Mallick et al. 2011, Benneyworth et al. 2016). On the other hand, shrimp farming which has intensified over the past several decades, negatively affects surface and groundwater resources (Datta et al. 2010, Benneyworth et al. 2016).

\section{Conclusions}

Landsat 8 OLI is proved to be applicable for detecting TDS level of coastal surface water, which has made the monitoring task very effective. Coastal water bodies are deteriorating day by day and increasing TDS level is one of the indications. Water areas with unacceptable TDS level $(>1200$ $\mathrm{mg} / \mathrm{L}$ ) has increased $32.7 \%$ within just last 4 years. As the surface water cannot be used for drinking and other domestic purposes as well as for irrigation, coastal people are becoming more dependent on the ground water. Dependence on ground water has increased due to the polluted and unacceptable surface water, which causes ground water depletion problem more acute. In a word, contamination of surface waters has led to freshwater scarcity and health hazard for the coastal people. Water contamination should be controlled by introducing integrated water resource management and water quality parameters should be monitored regularly for the betterment of coastal people.

\section{References}

Ahmed, M. J., Haque, M. R., and Rahman, M. M., 2011, Physicochemical assessment of surface and ground water resources of Noakhali region of Bangladesh. International Journal of Chemical Science and Technology, 1(1), 1-10.

Benneyworth, L., Gilligan, J., Ayers, J. C., Goodbred, S., George, G., Carrico, A., Karim, M. R., Akter, F., Fry, D., Donato, K., and Piya, B., 2016, Drinking water insecurity: water quality and access 
in coastal south-western Bangladesh. International Journal of Environmental Health Research, 1-17. DOI: 10.1080/09603123.2016.1194383.

Das, T. K., Choudhury, M., and Sultana, M., 2017, Determination of drinking water quality: a case study on saline prone south-west coastal belt of Bangladesh. Journal of Environmental Science and Natural Resources, 10(1), 101-108.

Datta, D. K., Roy, K., and Hassan, N., 2010, Shrimp culture: trend, consequences and sustainability in the southwestern coastal region of Bangladesh. In: Management and sustainable development of coastal zone environments, edited by A. L. Ramanathan, P. Bhattacharya, T. Dittmar, M. B. K. Prasad, and B. R. Nupane. (Dordrecht: Springer), pp. 227-244.

González-Márquez, L. C., Torres-Bejarano, F. M., Rodríguez-Cuevas, C., Torregroza-Espinosa, A. C., and Sandoval-Romero, J. A., 2018, Estimation of water quality parameters using Landsat 8 images: application to Playa Colorada Bay, Sinaloa, Mexico. Applied Geomatics, 10, 147-158.

Hellweger, F. L., Schlosser, P., Lall, U., and Weissel, J. K., 2004, Use of satellite imagery for water quality studies in New York Harbor. Estuarine, Coastal and Shelf Science, 61, 437-448.

Islam, M. R., Sarkar, M. K. I., Afrin, T., Rahman, S. S., Talukder, R. I., Howlader, B. K., and Khaleque, M. A., 2016, A Study on Total Dissolved Solids and Hardness Level of Drinking Mineral Water in Bangladesh. Americal Journal of Applied Chemistry, 4(5), 164-169.

Jothivenkatachalam, K., Nithya, A., and Mohan, S. C., 2010, Correlation analysis of drinking water quality in and around Perur Block of Coimbatore District, Tamil Nadu, India. Rasayan Journal of Chemistry, 3(4), 649-654.

Karakaya, N., Evrendilek, F., Aslam, G., Gungor, K., and Karakas, D., 2011, Monitoring of lake water quality along with trophic gradient using landsat data. International Journal of Environmental Science and Technology, 8(4), 817-822.

Khan, A. E., Ireson, A., Kovats, S., Mojumder, S. K., Khusru, A., Rahman, A., and Vineis, P., 2011, Drinking water salinity and maternal health in coastal Bangladesh: implications of climate change. Environmental Health Perspective,119(9), 1328-1332.

Kulkarni, A., 2011, Water Quality Retrieval from Landsat TM Imagery. Procedia Computer Science, $6,475-480$.

Lim, H. S., Jafri, M. Z. M., Abdullah, K., Alias, A. N., Wong, C. J., Mustapha, M. R., Saleh, N. M., 2009, Water Quality Mapping Using Landsat TM Imagery. Proceedings of SPIE - The International Society for Optical Engineering, Orlando, Florida, USA, April.

Mallick, B., Rahman, K. R., Vogt, J., 2011, Coastal livelihood and physical infrastructure in Bangladesh after cyclone Aila. Mitigation and Adaptation Strategies for Global Change, 16(6), 629648.

McFeeters, S. K., 1996, The use of the normalized difference water index (NDWI) in the delineation of open water features. International Journal of Remote Sensing, 17(7), 1425-1432.

Miah, M. Y., Robel, F. N., Bhowmik, S., Bhattacharjee, S., Paul, S. C., Hossain, M. J., and Hossain, M. Z., 2015, Assessment of the coastal area water quality in Noakhali, Bangladesh. International Journal of Scientific \& Engineering Rewards, 6(2), 1116-1123.

Pásler, M., Komárková, J., 2016, Utilization of Landsat data for water quality observation in small inland water bodies. The International Archives of the Photogrammetry, Remote Sensing and Spatial Information Sciences, XLI-B8, 373-377. 
Pavelsky, T. M., and Smith, L. C., 2009, Remote sensing of suspended sediment concentration, flow velocity, and lake recharge in the Peace- Athabasca Delta, Canada. Water Resources Research, 45(11).

Rahman, M. T. U., Rasheduzzaman, M., Habib, M. A., Ahmed, A., Tareq, S. M., and Muniruzzaman, S. M., 2017, Assessment of fresh water security in coastal Bangladesh: An insight from salinity, community perception and adaptation. Ocean \& Coastal Management, 137, 68-81.

$\begin{array}{lllll}\text { Statistics Kingdom, Date of 20/08/2018. } & \text { access: }\end{array}$ http://www.statskingdom.com/410multi_linear_regression.html

Su, Y., Liou, J., Hou, J., Hung, W., Hsu, S., Lien, Y., Su, M., Cheng, K., and Wang, Y., 2008, A multivariate model for coastal water quality mapping using satellite remote sensing images. Sensors, 8, 6321-6339.

Yusop, S. M., Abdullah, K., San, L. H., and Bakar, M. N. A., 2011, Monitoring water quality from Landsat TM imagery in Penang, Malaysia. Proceeding of the 2011 IEEE International Conference on Space Science and Communication (IconSpace), Penang, Malaysia, July, pp. 249-253. 